Journal of Case Reports 2018;8(3):205-207

\title{
Femoropopliteal Bypass Surgery: Great Saphenous Vein Graft Rupture
}

\author{
Mundayat Gopalkrishnan ${ }^{1}$, Amith Kiran ${ }^{1}$, Kalale Radhakrishnan Bhagavan², Rohith Holla ${ }^{2}$, Anirudh Rajeev ${ }^{2}$ \\ Departments of ${ }^{1}$ Cardiothoracic \& Vascular Surgery and ${ }^{2}$ General Surgery, KS Hegde Medical Academy, Manglore, Karnataka, \\ India.
}

\section{Corresponding Author: \\ Dr. Mundayat Gopalkrishnan \\ Email: drmgk23@hotmail.com}

This is an Open Access article distributed under the terms of the Creative Commons Attribution License (creativecommons.org/ licenses/by/3.0).

Received : November 27, 2017

Accepted : July 13, 2018

Published : August 30, 2018

\begin{abstract}
Background: Great saphenous vein (GSV) graft is commonly used for peripheral arterial reconstructions. Pseudo-aneurysm of GSV graft is a rare entity. It can be associated with high morbidity and can be prevented by technical modifications. We hereby report pseudoaneurysm of great saphenous vein (GSV) graft. Case Report: Our patient underwent femoro-popliteal bypass surgery after excision of degenerative pseudo-aneurysm of the left superficial femoral artery one month ago. The vein graft tear following aneurysmal rupture was patched up with polytetrafluoroethylene (PTFE) patch. Patient had his limb saved by a repaired vein graft. We are highlighting the clinical pictures of this rare entity and also describing the management options for it. Conclusion: With early diagnosis and intervention, potentially dangerous and rare clinical condition like GSV graft pseudoaneurysm can be tackled with good result.
\end{abstract}

Keywords: Aneurysm Rupture, Femoral Artery, Saphenous Vein, Polytetrafluoroethylene.

\section{Introduction}

Great saphenous vein (GSV) grafts are commonly used as bypass conduit for lower limb revascularisation due to its advantages over the synthetic graft in terms of durability and complication free outcomes [1]. GSV bypass graft aneurysm rupture is a rare entity with an incidence $<1 \%$ but can prove to be fatal if goes unrecognised [2]. This can be prevented by technical modifications.

\section{Case Report}

A 62 year old male presented with pain and swelling of left lower limb. His computerised tomographic (CT) angiogram showed pseudo-aneurysm (PA) of distal $1 / 3$ left superficial femoral artery (SFA) of size $8.3 \times 7.6 \times 2.5 \mathrm{~cm}$. He underwent left femoropopliteal (FP) bypass with GSV graft after excision of PA. The specimen was reported as vascular wall with degenerative changes. One month later patient again presented with left lower limb pain and diffuse swelling in antero-medial aspect of thigh with skin discolouration. The swelling corresponds to the GSV graft site, had transmitted pulsations and bruit. Left lower limb had absent popliteal, anterior tibial, posterior tibial and dorsalis pedis pulsations. Ankle brachial pressure index (ABPI) on admission was 0.6. The screening CT showed aneurysm of distal limb of GSV bypass graft of $3 \times 2.5 \mathrm{~cm}$.

Patient was taken up for emergency reoperation while being prepared for elective surgery because of sudden massive bleeding from the aneurysm. Left antero-medial thigh re-exploration was done through previous incision after isolating left common femoral artery through a groin incision. Left SFA was delineated along with GSV graft, a popped off silk ligature from the side branch was noted. A tear of about $2.5 \mathrm{~mm}$ was noted with surrounding hematoma. The hematoma was cleared from the operative field, hemostasis was achieved through vascular clamp application across interposition graft. 
The tear was noted in GSV graft which was closed with a polytetrafluoroethylene (PTFE) graft patch. Post-PTFE patching of tear and after the release of bulldog clamps, good flow was noted. Adequate vascularity of the left lower limb was maintained. After the redo procedure he had an uneventful course. Left lower limb peripheral pulses were felt clinically and heard sonologically. ABPI came to 1. A check Colour Doppler was done, graft was found to be patent. Patient remained in perfect clinical status at the latest follow up one month later.

\section{Discussion}

The autologous saphenous vein is commonly used in vascular surgery as bypass graft for relief of limb ischemia and reconstruction of lower limb arteries. Complications after surgical bypass include wound infection, necrosis, tissue loss, graft occlusion and bleeding [1]. Aneurysm refers to the dilatation of the vessel wall $>1.5$ times the normal vessel caliber. GSV graft aneurysm incidence is about $2 \%$. Pseudoaneurysm (PA) can develop as a delayed presentation in surgically revascularized patients. Given the rising number of reconstructive vascular procedures, the increase in anastomotic PA cases is expected [2].

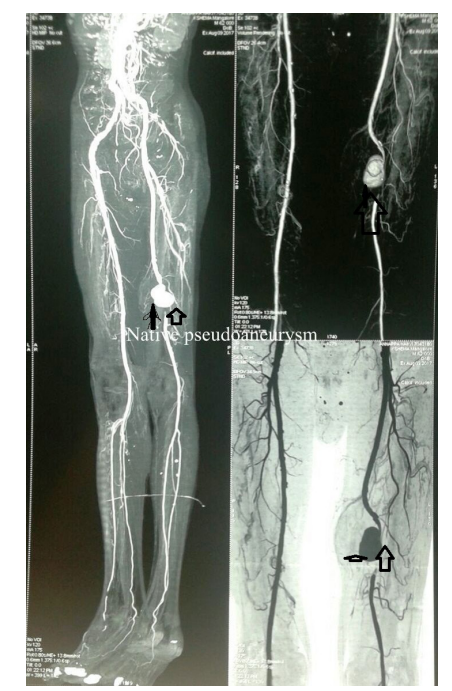

Fig.1: Pre-operative CT-peripheral angiogram showing left SFA distal 1/3 pseudo-aneurysm. Arrow highlights the aneurysm.

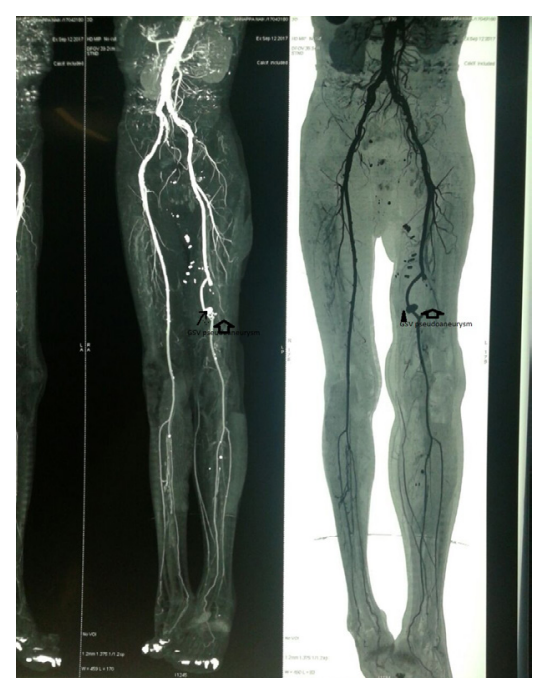

Fig.2: CT peripheral angiogram showing aneurysm in distal limb of GSV graft. Arrow highlights the aneurysm.

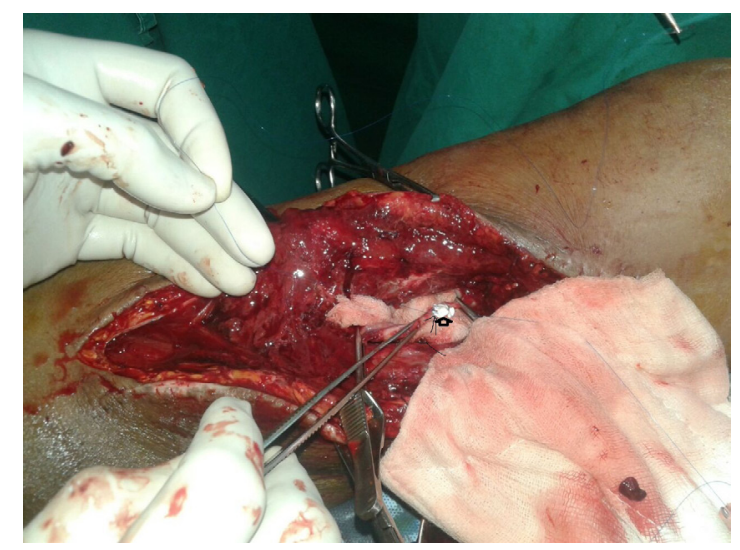

Fig.3: On table hematoma evacuation and bulldog vascular clamp application.

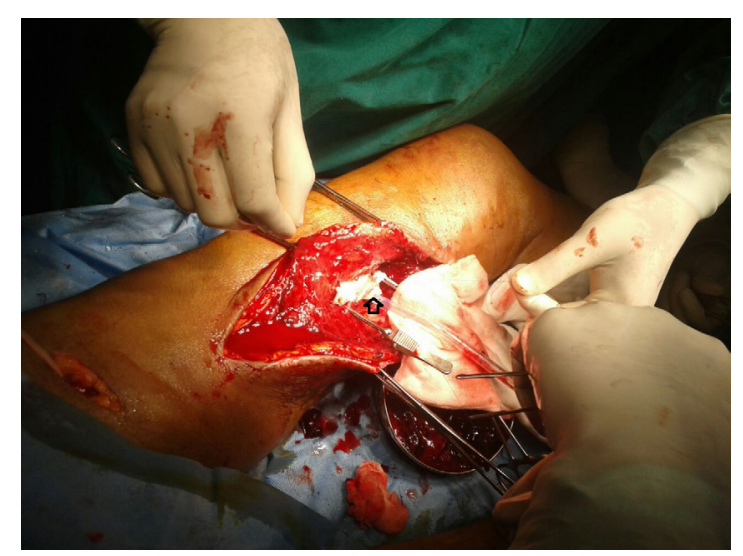

Fig.4: Vein bypass graft closure done with PTFE patch and 5-0 prolene. 
The clinical presentation of PA may vary from patient to patient. Compressive symptomatology compromises only $10 \%$ of presenting patients. Other presentations include acute and chronic limb ischemia, bleeding secondary to rupture and an asymptomatic pulsatile mass [2]. Although the majority of PA is secondary to trauma or iatrogenic injury, other etiologic factors are post-operative infections, suture fatigue, poor suture material, post-operative nicotine use, recurrent operations to the same site and mechanical obstruction [2]. If left untreated, PA may lead to thrombosis, rupture or distal embolization [2].

Indications to repair a PA include active hemorrhage, impending compartment syndrome and severe unremitting pain. In high-surgical-risk patients, the placement of a stent graft provides a safe and effective option for the treatment of PA $[3,4,5]$. Although stenting of PA has been reported in the literature for over a decade, reports of endoluminal stent graft placement to treat false aneurysms of infra-inguinal bypass grafts are few [5]. There is one case of GSV aneurysm reported after 20 years of femoro-popliteal bypass which was treated by excision and PTFE graft replacing the GSV [6].

In our patient his native PA was repaired surgically because of its location and the excellent results reported for GSV grafts. His second presentation with leaking PA mandated surgical repair due to major bleeding and skin erosion. The cause of his native aneurysm was degenerative but recurrent aneurysm was result of slipped ligature from a venous branch of the GSV graft. During reexploration adequate control of bleeding and continued patency of the graft was ensured.

\section{Conclusion}

The development of a swelling at the site of graft region might mean more than a quiescent hematoma, it may be an aneurysm with impending risk of rupture with an ability to cause mortality. Close monitoring, stringent post-operative follow up, timely intervention are essential in treating these patients. We therefore would like to conclude our paper stating that "A nick in time saves nine".

Contributors: MG, AK: manuscript editing, patient management; KRB: critical inputs into the manuscript; RH, AR: manuscript writing, patient management; $M G$ will act as guarantor. All authors approved the final version of this manuscript.

Funding: None; Competing interests: None stated.

\section{References}

1. John TG, Stonebridge PA, Kelman J, Murie JA, Jenkins AM, Ruckley CV. Above knee femoropopliteal bypass grafts and consequences of graft failure. Annals of Royal College of Surgeons of England. 1993;75:257-260.

2. Carollo A, Gagliardo G, DeVito PM, Cicchillo M. Stent graft repair of anastomotic pseudoaneurysm of femoralpopliteal bypass graft following patch angioplasty. J Surg Case Rep. 2016(12);rjw198.

3. Garge S, Vyas P, Rathod K, Jaggi S, Talwar I. Leaking pseudoaneurysm of lower limb saphenous vein graft: a rare complication and its successful treatment by endovascular embolization. BJR Case Reports 2017;3:1.

4. Saad NE, Saad WE, Davies MG, Waldman DL, Fultz PJ, Rubens DJ. Pseudoaneurysms and the role of minimally invasive techniques in their management. Radiographics. 2005;25Suppl 1:S173-189.

5. Rajachandran M, Klym K, Salvaji M. A quick fix: graft rescue for iatrogenic pseudoaneurysm. J Invasive Cardiol. 2007;19:E19-22.

6. Schmitto JD, Coşkun KO, Coşkun ST, Mokashi SA, Popov AF. Saphenous venous bypass graft aneurysm following femoropopliteal bypass surgery. Turkish Journal of Thoracic and Cardiovascular Surgery. 2012;20:370-373. 